Elsevier Editorial System(tm) for Accident Analysis \& Prevention

Manuscript Draft

Manuscript Number:

Title: ANALYSIS OF LARGE TRUCK CRASH SEVERITY USING HETEROSKEDASTIC ORDERED PROBIT MODELS

Article Type: Full Length Paper

Keywords: Long-combination vehicles, crash severity, heavy duty truck safety, heteroskedasticity, ordered probit

Corresponding Author: Dr. Kara M. Kockelman, PhD

Corresponding Author's Institution: The University of Texas @ Austin

First Author: Jason Lemp, PhD

Order of Authors: Jason Lemp, PhD; Kara M. Kockelman, PhD; Avinash Unnikrishnan, PhD

Abstract: Long-combination vehicles (LCVs) have significant potential to increase economic productivity for shippers and carriers by decreasing the number of truck trips, thus reducing costs. However, size and weight regulations, triggered by safety concerns and, in some cases, infrastructure investment concerns, have prevented large-scale adoption of such vehicles. Information on actual crash performance is needed. To this end, this work uses standard and heteroskedastic ordered probit models, along with the United States' Large Truck Crash Causation Study, General Estimates System, and Vehicle Inventory and Use Survey data sets, to study the impact of vehicle, occupant, driver, and environmental characteristics on injury outcomes for those involved in crashes with heavy-duty trucks. Results suggest that the likelihood of fatalities and severe injury is estimated to rise with the number of trailers, but fall with the truck length and gross vehicle weight rating (GVWR). While findings suggest that fatality likelihood for two-trailer LCVs is higher than that of single-trailer nonLCVs and other trucks, controlling for exposure risk suggest that total crash costs of LCVs are lower (per vehicle-mile traveled) than those of other trucks. 


\title{
ANALYSIS OF LARGE TRUCK CRASH SEVERITY USING HETEROSKEDASTIC ORDERED PROBIT MODELS
}

\author{
Jason D. Lemp, PhD \\ Senior Professional \\ Cambridge Systematics \\ 9015 Mountain Ridge Drive, Suite 210 \\ Austin, TX 78759 \\ lemp5000@yahoo.com \\ Kara M. Kockelman \\ Professor of Civil, Architectural and Environmental Engineering \\ The University of Texas at Austin \\ 6.9 E. Cockrell Jr. Hall, Austin, TX 78712-1076 \\ kkockelm@mail.utexas.edu \\ Phone: 512-471-0210 \\ FAX: 512-475-8744 \\ (Corresponding Author) \\ Avinash Unnikrishnan \\ Assistant Professor \\ Civil and Environmental Engineering \\ West Virginia University \\ Morgantown, WV 26506-6103 \\ avinashu@gmail.com
}

Submitted for publication to Accident Analysis \& Prevention-March 2010

\begin{abstract}
Long-combination vehicles (LCVs) have significant potential to increase economic productivity for shippers and carriers by decreasing the number of truck trips, thus reducing costs. However, size and weight regulations, triggered by safety concerns and, in some cases, infrastructure investment concerns, have prevented large-scale adoption of such vehicles. Information on actual crash performance is needed. To this end, this work uses standard and heteroskedastic ordered probit models, along with the United States' Large Truck Crash Causation Study, General Estimates System, and Vehicle Inventory and Use Survey data sets, to study the impact of vehicle, occupant, driver, and environmental characteristics on injury outcomes for those involved in crashes with heavy-duty trucks. Results suggest that the likelihood of fatalities and severe injury is estimated to rise with the number of trailers, but fall with the truck length and gross vehicle weight rating (GVWR). While findings suggest that fatality likelihood for twotrailer LCVs is higher than that of single-trailer non-LCVs and other trucks, controlling for exposure risk suggest that total crash costs of LCVs are lower (per vehicle-mile traveled) than those of other trucks.
\end{abstract}


Keywords: Long-combination vehicles, crash severity, heavy duty truck safety, heteroskedasticity, ordered probit

\section{INTRODUCTION}

Larger trucks can increase economic productivity by increasing cargo capacity per trip. This is believed to result in reduced overall transportation and fuel costs and emissions due to fewer truck trips (Caltrans 2009). As a result, use of long combination vehicles (LCVs) ${ }^{1}$ is increasing, both in terms of total vehicle miles traveled (VMT) as well as proportion of vehicles on U.S. and Canada's highways (Abdel-Rahim et al. 2006). Nevertheless, truck size and weight regulations, in large part motivated by safety concerns, have greatly limited the large-scale adoption of larger vehicles. The 1991 Intermodal Surface Transportation Efficiency Act (ISTEA) froze LCV operations on interstates to only those authorized by state governments before June 1, 1991 . Currently, operation of three LCV configurations ${ }^{2}$ is permitted on designated routes in twelve states: Alaska, Arizona, Colorado, Idaho, Indiana, Kansas, Montana, Nevada, North Dakota, Oklahoma, South Dakota and Utah. Other, specific configurations are permitted on selected routes in six other states (AASHTO 1995).

Identifying factors which affect large-truck safety is essential for developing policies and regulations that enable LCV operations without compromising safety and efficiency. The number of large trucks involved in fatal and non fatal crashes increased by 5.9\% from 2004 to 2007 (FMCSA 2009), while VMT for these vehicles increased by 135\% (FMCSA 2009). In general, analysis of LCV safety relative to other heavy-duty trucks (HDTs) has been difficult, due to a lack of data involving LCVs (GAO 1992, USDOT 2000, and Craft 1999).

This work examined hundreds of factors affecting crash severity for persons involved in HDT crashes by analyzing records in the recent Large Truck Crash Causation Study Data (LTCCS), provided by the U.S. Federal Motor Carrier Safety Administration (FMCSA) and National Highway Traffic Safety Administration (NHTSA). Standard ordered probit and heteroskedastic ordered probit (OP and HOP) models were used to illuminate the impact of various truck, environmental and occupant characteristics on injury outcomes.

The next section provides a detailed overview of related research and motivates the need for this work. The model structure of the OP and HOP models is then discussed, along with formulae for calculating marginal effects of control variables and data sets used. Finally, model results and conclusions are provided.

\footnotetext{
1 In the United States, LCVs are defined as heavy-duty trucks greater than 80,000 lbs gross vehicle weight rating (GVWR) with two or more trailers and at least one such trailer longer than 28 feet. In Canada, LCVs are defined as heavy-duty trucks with two or more trailers and total length greater than $25 \mathrm{~m}$ (about $82 \mathrm{ft}$ ).

${ }^{2}$ The three LCV configurations operating in the U.S. are the Rocky Mountain Double (two trailers, with the first 48 feet long and second trailer $28.5 \mathrm{ft}$ long), the Turnpike Double (two 48' trailers), and the Triple (three 28.5' trailers).
} 


\section{LITERATURE REVIEW}

Researchers have adopted two approaches to the study of large truck and LCV safety. The first approach emphasizes operational characteristics and large truck design requirements, as compared to other trucks and roadway geometry, in order to anticipate real-world safety impacts (Caltrans 1983, Harkey et al. 1996, Hanley et al. 2005, Glaeser et al. 2006, Debauche et al. 2007, Renshaw 2007, and Knight et al. 2008). The second approach to large truck and LCV safety evaluation involves analysis of actual crash rates and outcomes, in order to identify general trends and relationships.

Based on the crash histories of multiple-trailer trucks, a USDOT (2000) study concluded that trucks pulling more than two trailers are likely to be involved in $11 \%$ more crashes per mile traveled than single trailer trucks, when both trucks are operated under similar conditions (USDOT 2000). However, LCVs carry more cargo, so their crash-rate per ton-mile can be significantly lower. And crash-severity differences can go either way, as discussed below.

Truck length is a key variable. Vierth et al. (2008) conducted an analysis of 2003 to 2005 accident data in Sweden to check if the presence of longer trucks results in more overtakingrelated crashes and concluded that the increase in accident risk is not statistically significant and is offset by truck-miles reductions (thanks to bigger cargos).

Campbell et al. (1989) surveyed 12 western states where LCV operations were permitted and identified around 550 police-reported crashes involving LCVs. The accident rates were found to be lower than what was expected for combination vehicles, either due to under-reporting or the presence of operational restrictions on LCVs. Using the general estimates system (GES) data from the National Highway Traffic Safety Administration (NHTSA) for the years 1989-1993, Wang et al. (1999) concluded that combination-unit-trucks enjoy significantly lower crash rates as compared to passenger vehicles and single-unit trucks (at rates of 226 combination-unit crashes per 100 million miles traveled, versus 556 for passenger vehicles, 416 for light-duty trucks, and 289 for single-unit trucks).

Using Alberta, Canada data from 1995 to 1998, Woodrooffe (2001) compared LCV safety to that of other vehicle classes. He determined that the LCVs enjoy the lowest collision rates (per miletraveled) among all vehicle classes in that region, with fewer than 14 involved LCVs per year. The number of LCV collisions that occurred in rural areas was roughly twice the number of such incidents in Alberta's urban areas. Montufar et al. (2007) conducted a similar study in the Alberta region from 1999 to 2005, to compare and contrast safety performance over the study periods. Their work revealed LCVs to be the safest among all vehicle types, with just 40 collisions for every 100 million miles traveled plus the lowest injury and fatality rates. Driving actions such as improper turning and lane change maneuvers and unsafe roadway conditions such as presence of snow, ice, slush or rain were the major causes of LCV related incidents (Montufar et al. 2007). Abdel-Rahim et al. (2006) obtained similar results from analyzing LCV crash data in Idaho, Montana, Oregon and Utah. 
Several European countries have been studying the feasibility of using longer, heavier vehicles $(\mathrm{LHVs})^{3}$ for freight transport. Debauche et al.'s (2007) safety survey of roughly 100 LHVs for the Dutch Ministry of Transport estimated LHVs to have similar levels of safety when compared to heavy goods vehicles (HGVs) ${ }^{4}$ - and slightly lower fatal injury crash counts (totaling just 4 to 25 such crashes a year in the Netherlands). Motorists also did not report any decrease in perceived safety level in the presence of a LHV, as opposed to a regular HGV.

While crash rates may be significantly lower, LCVs and combination trucks have been found to result in higher casualty rates, per crash (Vierth et al. 2008 and Zaloshnja et al. 2000), and higher crash costs per incident (Zaloshnja et al. 2000, Wang et al. 1999, Zaloshnja and Miller 2004, and Zaloshnja and Miller 2007). Nonetheless, Zaloshnja and Miller (2004) concluded that the lower crash rates of LCVs outweigh their higher crash costs, making LCVs safer per vehicle-mile traveled than other HDTs.

Forkenbrock et al. (2003) used multiple classification analysis and automatic interaction detectors for a 1995-1998 Trucks Involved in Fatal Accidents (TIFA) data file, as maintained by the University of Michigan Transportation Research Institute (UMTRI). They concluded that multiple-trailer trucks have a higher likelihood of crash involvement when compared to singletrailer trucks under difficult driving conditions. Such conditions include darkness, snow on the road, and moderate traffic volumes on reasonably high-speed facilities.

In the United Kingdom, Knight et al. (2008) found that $18.3 \%$ of traffic fatalities involved one $\mathrm{HGV}$, even though they accounted for less than $6 \%$ of VMT. The three main factors affecting fatal-outcome likelihood were found to be collision speed, mass of the two vehicles, and type of impact. Of course, the higher the collision speed, the more severe the crash. Interestingly, as the ratio of vehicle masses increases beyond 50:1 (as is generally the case with LHVs), there was no significant change in incident severity for the passenger vehicle occupants - assuming there are no secondary incidents. The likelihood of death for an HGV occupant is low, as long as the truck can absorb some of the crash impact (as is the case with most HGV-passenger car accidents). Knight et al. (2008) noted that the presence of Collision Mitigating Braking Systems (CMBS) has the potential to reduce heavy vehicle crash frequencies by up to $75 \%$, and an even greater percentage for LHVs (Grover et al. 2007 and Knight et al. 2008).

By extrapolating the UK casualty rate data, Knight et al. (2008) concluded that casualty risks will increase with the number of axles. However, they acknowledge that the methodology they adopted significantly overestimates LHV risks. No trends were observed when fatality rates were extrapolated over gross vehicle weights. They also concluded that LHVs are more likely to be involved (around 5 to 10\% more) in severe accidents as compared to standard trucks, assuming that no additional safety measures are employed in LHV use.

Recently, Knipling et al. (2008) used the U.S.'s Large Truck Crash Causation Study (LTCCS), which contains information on 963 crashes involving 1,241 trucks between 2001 and 2003, to compare combination-truck and single-unit truck crashes. They examined 44 variables characterizing crash type, driver characteristics, driving environment and vehicle type. The

\footnotetext{
${ }^{3}$ LHVs are vehicles longer than $54 \mathrm{ft}$. and heavier than 44 metric tonnes (RoadTransport, 2009).

${ }^{4}$ HGVs are those vehicles weighing more than $3500 \mathrm{~kg}$, or $7714 \mathrm{lbs}$ (ERSO, 2009).
} 
percentage of crashes in dark conditions was found to be three times higher for combination trucks when compared to single-unit trucks.

Of course, LCVs do not always operate under the same conditions as other HDTs. For instance, LCV drivers are usually better-trained and have more experience than other HDT drivers in Canada and the U.S. (Abdel-Rahim 2009 and Regehr 2009). In addition, certain LCV operations may favor nighttime travel, and LCV use is often prohibited during times of heavy congestion in large Canadian cities (Regehr 2009 and Woodrooffe 2009). Abdel-Rahim (2009) has suggested that many U.S. states prohibit LCV use in bad weather conditions, and often restrict their use to routes with the most ideal geometric designs (such as interstate highways).

In general, no study has been able to conclusively determine whether larger trucks decrease safety levels overall. Much analysis has been based on simple rate comparisons and univariate or bivariate cross-tabulations. This paper uses ordered probit models to analyze injury severity for crashes involving at least one truck with a gross vehicle weight rating over 10,000 pounds. In addition, simulated outcomes are generated and combined with crash cost and HDT crash rate data to examine exposure risk of LCVs versus other HDTs. Ordered probit models have been used to analyze crash severity of automobile crashes (Khattak et al. 1998, 2002, Kockelman and Kweon 2002, 2003, Abdel Aty 2003, and Khattak and Rosa 2003), with O'Donnell and Connor (1996) and Wang and Kockelman (2005) using heteroskedastic ordered probit and logit models to analyze injury severity. The next section describes the model specification used in this study.

\section{MODEL STRUCTURE}

A standard ordered probit (OP) model assumes that ordinal discrete responses can be modeled using a latent continuous variable expressed as a function of explanatory variables and an error term, as follows:

$$
U_{i}=X_{i}{ }^{\prime} \beta+\varepsilon_{i} \quad \forall i=1, \ldots, N
$$

where $i$ is an index for an observation or individual, $U_{i}$ represents the latent continuous dependent variable, $X_{i}$ is vector of explanatory variables, $\beta$ is a column vector of coefficients (to be estimated), and $\varepsilon_{i}$ is an error term representing all unobserved characteristics affecting the crash outcome. In OP models, $\varepsilon_{i}$ is modeled as a random variable following an i.i.d normal distribution (with variance $\sigma^{2}$ ) for all observations.

The observed variable $y_{i}$ for the $i^{\text {th }}$ observation can take ordinal discrete values ranging from 1 to $S$. The observed variable $y_{i}$ is related to the continuous latent variable $U_{i}$ as follows:

$$
y_{i}=s \text { if } \mu_{s-1}<U_{i}<\mu_{s} \quad s=1, \ldots, S
$$

where $\mu_{s}$ denotes the boundary points or thresholds for the latent continuous variable $U_{i}$ such that $\mu_{0}<\mu_{1}<\cdots<\mu_{S}$. Since latent variables can assume any real numbered value, the first and last thresholds are set to $\pm \infty$ (i.e., $\mu_{0}=-\infty$ and $\mu_{S}=\infty$ ). For the purpose of statistical identification, two other model parameters must be fixed as well. In this case, the second and 
third threshold parameters are set to 0 and 1 (i.e., $\mu_{1}=0$ and $\mu_{2}=1$ ). The probability of observed variable $y_{i}$ taking an outcome value $s$ is given by:

$$
P\left(y_{i}=s\right)=\Phi\left(\frac{\mu_{S}-X_{i^{\prime}} \beta}{\sigma}\right)-\Phi\left(\frac{\mu_{s-1}-X_{i^{\prime}} \beta}{\sigma}\right)
$$

where $\Phi($.$) represents the standard-normal cumulative distribution function.$

In many cases, error terms may not be homoskedastic, and their variance may be parameterized as a function of covariates. In such cases, a heteroskedastic ordered probit (HOP) model is used, where the variance of observation $i$ 's error term, $\sigma_{i}^{2}$, is expressed as follows:

$$
\sigma_{i}^{2}=\left[\exp \left(Z_{i}^{\prime} \gamma\right)\right]^{2}
$$

In the above equation, $Z_{i}$ and $\gamma$ represent vectors of explanatory variables and their associated coefficients, respectively. The probability of observed variable $y_{i}$ taking an outcome value $s$ is given by:

$$
P\left(y_{i}=s\right)=\Phi\left(\frac{\mu_{s}-X_{i^{\prime}} \beta}{\sigma_{i}}\right)-\Phi\left(\frac{\mu_{s-1}-X_{i^{\prime}} \beta}{\sigma_{i}}\right)
$$

The likelihood function of either model (OP or HOP) can be written as shown below:

$$
L=\prod_{i=1}^{N}\left[\sum_{S=1}^{S} \delta\left(y_{i}=s\right)\left(\Phi\left(\frac{\mu_{s}-X_{i^{\prime}} \beta}{\sigma_{i}}\right)-\Phi\left(\frac{\mu_{s-1}-X_{i^{\prime}} \beta}{\sigma_{i}}\right)\right)\right]^{w_{i}}
$$

where $w_{i}$ represents the population expansion factor (or crash-record weight, as provided by the LTCCS data) for the $i^{\text {th }}$ observation, and $\delta(A)$ is an indicator variable taking a value of 1 if event $A$ is true and 0 otherwise. In the OP case, $\sigma_{i}=\sigma \forall i$.

This paper uses Bayesian techniques to estimate the two models. Denoting the set of independent variables as $X$ and the set of response variables as $Y$, the Bayesian posterior distribution is written as follows (Gelman et al. 2004):

$$
p(\beta, \gamma, \mu \mid Y, X) \propto p(Y \mid \beta, \gamma, \mu, X) \pi(\beta, \gamma, \mu)
$$

where $p(Y \mid \beta, \gamma, \mu, X)$ represents the likelihood function (shown in equation 6$)$ and $\pi(\beta, \gamma, \mu)$ is the prior distribution of model parameters (reflecting the analyst's prior beliefs). In the standard Bayesian construction of the probit model (see, e.g., Albert and Chib 1993 and McCulloch and Rossi 1994), latent variables, $U_{i}$, are assumed to be random (nuisance) parameters to be estimated. In this context, the likelihood function can be rewritten as follows:

$$
L=\prod_{i=1}^{N}\left[\delta\left(\mu_{y_{i}-1}<U_{i}<\mu_{y_{i}}\right) \pi\left(U_{i} \mid \beta, \sigma_{i}, X_{i}\right)\right]^{w_{i}}
$$


Here, $\delta\left(\mu_{y_{i}-1}<U_{i}<\mu_{y_{i}}\right)$ takes a value of 1 if $U_{i}$ is between $\mu_{y_{i}-1}$ and $\mu_{y_{i}}$, and $\pi\left(U_{i} \mid \beta, \sigma_{i}, X_{i}\right)$ represents our prior density of $U_{i}$ (i.e., a normal with mean $X_{i}^{\prime} \beta$ and variance $\sigma_{i}^{2}$ ). Using this notation, the posterior density of model parameters can be rewritten:

$$
p\left(U, \beta, \sigma_{i}, \mu \mid Y, X\right) \propto \prod_{i=1}^{N}\left[\delta\left(\mu_{y_{i}-1}<U_{i}<\mu_{y_{i}}\right) \pi\left(U_{i} \mid \beta, \sigma_{i}, X_{i}\right)\right]^{w_{i}} \pi\left(\beta, \sigma_{i}, \mu\right)
$$

The prior distributions of parameters are assumed independent of one another such that $\pi\left(\beta, \sigma_{i}, \mu\right)=\pi(\beta) \pi\left(\sigma_{i}\right) \pi(\mu)$. The prior for $\beta$ is taken to be normal with mean $\bar{\beta}$ and covariance matrix $\Sigma_{\beta}$ and the prior on $\mu$ is taken to be non-informative (i.e., proportional to 1 ). In the case of the OP model, the prior on $\sigma^{2}$ is inverse gamma with shape and scale parameters $q$ and $r$, and in the case of the HOP model, the prior on $\gamma$ is taken to be normal with mean $\bar{\gamma}$ and covariance matrix $\Sigma_{\gamma}$.

Bayesian estimation for both model specifications proceeds by drawing each set of parameters from their conditional posterior distribution via a four-step Gibbs sampler as follows:

Step 1: Draw $U_{i} \mid \beta, \sigma_{i}, \mu, X_{i}, Y_{i} \forall i$

Step 2: Draw $\beta \mid U, \sigma, \mu, X, Y$

Step 3: Draw $\mu \mid U, \beta, \sigma, X, Y$

Step 4: Draw $\sigma_{i} \mid U_{i}, \beta, \sigma_{i}, X_{i}, Y_{i} \forall i$

For latent variable, $U_{i}$, the conditional posterior distribution is truncated normal with mean $X_{i}{ }^{\prime} \beta$, variance $\sigma_{i}^{2}$, and lower and upper bounds of $\mu_{y_{i}-1}$ and $\mu_{y_{i}}$.

The conditional posterior distribution of $\beta$ can be written as follows:

$$
p(\beta \mid U, \sigma, \mu, X, Y) \propto \prod_{i=1}^{N}\left[\pi\left(U_{i} \mid \beta, \sigma_{i}, X_{i}\right)\right]^{w_{i}} \pi(\beta)
$$

Since $\pi\left(U_{i} \mid \beta, \sigma_{i}, X_{i}\right)$ and $\pi(\beta)$ are both normal densities, it can be shown through some simple manipulation that $\beta$ is distributed normally with mean given by $C$ and covariance matrix given by $D$, where $C$ and $D$ are defined as follows:

$$
\begin{aligned}
& C=D\left(X^{\prime} W U+\Sigma_{\beta}{ }^{-1} \bar{\beta}\right) \\
& D=\left(X^{\prime} W X+\Sigma_{\beta}{ }^{-1}\right)^{-1}
\end{aligned}
$$

Here, $W$ is a matrix with off-diagonal elements of zero and diagonal elements equal to $w_{i} / \sigma_{i}^{2}$. In this work, the prior mean vector, $\bar{\beta}$, was set to zeros and the prior covariance matrix, $\Sigma_{\beta}$, was set to zeros on off-diagonal elements and 100 on all diagonal elements (providing essentially no information to the model).

Since the prior is non-informative and the likelihood function only offers bounds on the parameters, the $\mu$ values can be drawn from uniform distributions with lower and upper bounds given by $\max _{i \in Q_{s-1}}\left(U_{i}\right)$ and $\min _{i \in Q_{s}}\left(U_{i}\right)$, where $Q_{s}$ is the set of all observations such that $y_{i}=$ $S$. 
In the final step, $\sigma_{i}$ is drawn from its conditional posterior distribution. For the OP specification, $\sigma_{i}=\sigma$ and $\sigma^{2}$ 's prior is inverse gamma, resulting in the following conditional posterior distribution:

$$
p\left(\sigma^{2} \mid U, \beta, \mu, X, Y\right) \propto\left(\frac{1}{\sigma^{2}}\right)^{N / 2+r+1} \exp \left(-\frac{0.5 \sum_{i} w_{i}\left[U_{i}-X_{i}{ }^{\prime} \beta\right]^{2}+q}{\sigma^{2}}\right)
$$

Thus, $\sigma^{2}$ is distributed inverse gamma with shape and scale parameters of $N / 2+r$ and $0.5 \sum_{i} w_{i}\left[U_{i}-X_{i}{ }^{\prime} \beta\right]^{2}+q$. Here, $r$ and $q$ were taken as one each (again providing the model very limited prior information).

For the HOP specification, $\sigma_{i}=\exp \left(Z_{i}^{\prime} \gamma\right)$ and $\gamma$ 's prior is normal. (Note that in this case, one must draw $\gamma$, not $\sigma_{i}$ directly.) Since the product of the likelihood and prior does not result in a standard density function, a normal random-walk Metropolis-Hastings (MH) step (see, e.g., Gamerman and Lopes 2006) is employed to draw $\gamma$. The conditional posterior density can be written as follows:

$$
p(\gamma \mid U, \beta, \mu, X, Y) \propto\left[\prod_{i=1}^{N}\left(\frac{1}{\sigma_{i}}\right)^{w_{i}}\right] \exp \left[-\frac{1}{2}\left(\sum_{i} \frac{w_{i}\left[U_{i}-X_{i^{\prime}} \beta\right]^{2}}{\exp \left[2 Z_{i^{\prime}} \gamma\right]}+[\gamma-\bar{\gamma}]^{\prime} \Sigma_{\gamma}{ }^{-1}[\gamma-\bar{\gamma}]\right)\right]
$$

Here, the prior mean, $\bar{\gamma}$, was chosen to be zero and the prior covariance matrix, $\Sigma_{\gamma}$, was set to zeros on the off-diagonal elements and 10 on the diagonal. Like the other priors, this prior offers very little information to the model (essentially allowing the data set $[n=922$ and $n=1,894$ for crash- and vehicle-level models] to determine all estimates).

Of course, the HOP model specification is more flexible than the OP, since it allows the variance term to vary for each observation. The OP is a special case, where all $\gamma_{t}$ are effectively zero (other than a constant). Wang and Kockelman (2005) used a similar specification for heteroskedastic ordered logit models of crash outcomes (with mostly light-duty vehicles) and found outcome variance (and thus outcome uncertainty) to rise with speed limit, and vary as a function of vehicle weight and vehicle type (with pickup trucks exhibiting higher uncertainty in all contexts, but weight and other vehicle types having different impacts depending on whether the crash involved one or two vehicles). O'Donnell and Conner (1996) found speed limit to increase variance and thus outcome uncertainty. Unlike these previous studies, this paper uses Bayesian estimation techniques, which offer a distribution of model parameters, rather than single point estimates. This allows the analyst to characterize crash severity outcome uncertainty in a meaningful way.

\section{DATA DESCRIPTION}

The primary data used here come from the Large Truck Crash Causation Study Data (LTCCS), collected by the United States' Federal Motor Carrier Safety Administration (FMCSA) and National Highway Traffic Safety Administration (NHTSA). Data were collected on crashes involving at least one truck with gross vehicle weight rating over 10,000 pounds, and an attempt was made during data collection to include only those crashes resulting in at least one injury or fatality (i.e., the three most severe crash types according to the KABCO injury scale). Trained 
staff from NHTSA's National Automotive Sampling Scheme (NASS) and state truck inspectors collected the LTCCS crash data in 24 data collection sites across 17 states between April 2001 and December 2003. The data collection efforts involved interviews with drivers, passengers, and witnesses.

Two collection sites were selected from each of the nation's 12 geographic areas. These areas were defined by four broad regions (northeast, midwest, south, and west), each broken into central city, large county, and county-group categories (as described in the LTCCS Codebook ${ }^{5}$ ). Analysts estimated a weight for each crash record to indicate how the data set can be expanded to provide a reasonably representative sample of the nation's injurious large-truck crashes. ${ }^{6}$ These weights are included in the likelihood functions of the models here.

Two response variables were of interest here, resulting in two different data sets. The first was vehicle-based, and used the maximum injury severity suffered by any vehicle occupant. While each vehicle in the dataset was involved in an injurious crash (i.e., the maximum injury severity sustained across all individuals in the crash was injurious or fatal), the maximum vehicle-level injury severity could be coded as any one of the five KABCO severities (including no injury, possible injury, non-incapacitating injury, incapacitating injury, and fatal). However, since there were so few vehicles coded in the "possible injury" category, it was grouped with the "no injury" category for a total of four possible outcomes. The second data set was crash-based, and was used to analyze the maximum injury severity suffered by any person involved in the crash. Since, each crash involved at least on injury or fatality, only three possible outcomes could be observed. Explanatory variables include a great variety of driver, environmental, and vehicle attributes, including the attributes of the truck involved. When multiple trucks were involved in a crash, the variables associated with the "largest truck" were used. Largest truck was defined as the truck having the most trailers (and then, in the event of a tie, the longest truck, and then the heaviest truck [according to GVWR]). In the model of occupant injury severity, 1,894 observations were used, after removing $8.9 \%$ of the records due to missing data. In studying the maximum injury severity, 922 observations were used (after deleting $4.2 \%$ of records for which variables were missing). Even after removing records because of missing data, a fairly large number of observations had missing data for the largest trucks length and GVWR (about $22 \%$ of crash observations). In order to preserve the sample and because these characteristics were viewed to be potentially important determinants of injury severity outcomes, average variable values were used when such data was missing. For single-unit trucks with no trailers, average length and GVWR were $30.5 \mathrm{ft}$ and 50,000 lbs. Average lengths for tractor trailers with 0, 1, and 2 trailers were 25.4, 64.0, and $71.5 \mathrm{ft}$, respectively, while average GVWRs for such vehicles were 52,900, 116,000, and 133,000 lbs, respectively.

As Table 1 values indicate, in the first data set (vehicle-level), 58.5\% of all cases experienced an injury, with fatalities for $4.1 \%$ of vehicle observations. In the second data set (crash-level), injuries were observed for $91.5 \%$ of the observations, and fatalities for $8.5 \%$.

\section{Table 1 goes here}

\footnotetext{
${ }^{5}$ The Codebook can be found at http://152.122.44.126/ltccs/data/documents/LTCCS_Codebook.pdf.

${ }^{6}$ Only those crashes where at least one injury or fatality occurred were given positive weights.
} 
Table 2 provides summary statistics for all variables used in the study. Variables are partitioned into three groups: crash-level variables, largest-truck (in crash) attributes, and vehicle and driver variables. All roadway characteristics (such as grade, curvature, classification, lanes, and speed limit) are shown in the largest-truck and vehicle/driver groups, as they pertain to the associated vehicle. The "other weather" indicator variable implies the presence of weather conditions other than rain, snow, or fog (e.g., wind, sleet, hail, and dust). The "other aggression" indicator refers to aggressive driving behavior other than speeding (e.g., tailgating, weaving in and out of traffic, violations of traffic control devices, rapid acceleration, honking horn, flashing lights, obscene gestures, and obstructing the path of others). Finally, uphill and downhill grades are defined as those exceeding $2 \%$.

\section{Table 2 goes here}

Data on driver, occupant, truck, and environmental characteristics were examined in a variety of initial model formulations. To arrive at final model specifications, variables that were found to have little practical and/or statistical significance were removed in a sequential variable elimination process. Some variables that were considered intuitively important were retained despite relatively low significance (e.g., the number of trucks and passenger vehicles and dark lighting conditions).

\section{SEVERITY MODEL RESULTS}

The final OP and HOP models (each with the same set of explanatory variables) were compared using total log-likelihood values (across all observations). Since Bayesian estimation output offers a collection of parameter draws from the posterior distribution, each draw is used to compute the likelihood each model would predict the actual severity outcome. Figure 1a illustrates the distributions of total log likelihoods for the OP and HOP models of vehicle injury severity, while Figure 1b illustrates these distributions for the models of crash injury severity.

\section{Figure 1 goes here}

As shown in Figure 1a, the HOP's likelihood dominates the OP's 100\% of the time. Mean loglikelihoods for the OP and HOP models are -1,993 and -1869 with standard deviations of 12.8 and 13.8, respectively. For the crash-level model (shown in Figure 1b), the HOP's likelihood beats the OP's almost $100 \%$ of the time. The mean OP log-likelihood is -779 with a standard deviation of 5.3, while the HOP's mean log-likelihood is -751 with a standard deviation of 6.5. Thus, it seems that heteroskedasticity cannot be neglected for either model, and the HOP model specifications are preferred. The results of these models are discussed below.

\section{Vehicle-Level Injury Severity Models}

Table 3 shows all parameter estimates for HOP and OP specifications of maximum injury severity at the vehicle level. While signs are generally consistent across the two models, one cannot readily appreciate most variables' full effects in the HOP model since most are estimated to affect both the mean and variance of our latent variable. To appreciate the overall impact of each HOP model covariate, Table 4 provides estimates of each variable's effects on crash 
severity probabilities. These are found by computing the probability of severity outcomes at various levels of each variable (e.g., indicator variables can be 0 or 1 , while number of occupants may vary from 1 to 10), and averaging the probability differences that emerge from the unit change differences in the explanatory factors. In other words, these represent average severity outcome probability changes per unit change in the variable.

\section{Table 3 goes here}

\section{Table 4 goes here}

Rows highlighted in light gray in Table 4 indicate variables that reduce the likelihood of fatality, while increasing the likelihood of no injury. Rows highlighted in dark gray in the Table indicate variables that increase the chance of fatality, while reducing the probability of no injury. The most practically significant variables are the number of passenger vehicles involved in the crash and an indicator for whether the observed vehicle is a bus or HDT: both increase the likelihood of their occupants departing the crash scene without a KAB injury. This is not a surprising result for the number of passenger vehicles, since each crash involves at least one injury across all involved. If there are more passenger vehicles involved in the crash, exposure risk is spread around, to some extent, leaving any particular vehicles' occupants better off. And larger vehicles, like buses and HDTs, may be safer for their vehicle occupants, by providing a great deal of impact protection from a large mass of yielding steel.

Other highly practically significant variables include the number of non-motorists involved, number of trailers of the largest truck involved, presence of fog, and whether the vehicle is a motorcycle. The number of involved non-motorists increases both the likelihood of fatality within each vehicle involved and the chance of no injury, thanks to greater uncertainty in injury severity. The number of trailers on the largest involved truck reduces the likelihood of no injury, while increasing the probability of each injury type. Of course, a great deal of correlation exists between this variable and the truck-specific variables for the largest involved HDT (i.e., the HDT's single-unit status, length, and GVWR), all of which increase the likelihood of no injury. Thus, drawing firm conclusions based solely on the largest truck's number of trailers may not be wise, and simulations are performed later in the paper to get at a more definitive direction of this effect. The presence of fog greatly reduces the no-injury outcome's likelihood, while greatly increasing the probability of a non-incapacitating injury (and largely maintaining other injury rates). Even though drivers are probably more cautious under such conditions, they simply do not have time to react to their surroundings due to sight distance impairment, which can lead to more injurious crashes. Finally, and not surprisingly, motorcycles fair very poorly in crashes. The probability of fatality for motorcycle riders involved in HDT crashes is estimated to be 30 percentage points higher than that of occupants in other passenger vehicles.

\section{Crash-Level Injury Severity Models}

Table 5 provides estimates for the injury severity models at the crash level. As in the vehiclelevel models, one must account for both mean and variance effects to fully appreciate how variables impact outcome probabilities. Table 6 provides estimates of average effects for each explanatory variable in the HOP model (as described earlier). Similar to Table 4, rows 
highlighted in light gray in Table 6 are variables that are estimated to reduce the likelihood of fatality while increasing the likelihood of non-incapacitating injury, while dark-gray rows are for variables that increase the chance of fatality and reduce the probability of non-incapacitating injury.

\section{Table 5 goes here}

\section{Table 6 goes here}

All non-bright conditions are estimated to increase the probability of fatality, perhaps because higher speed variations exist at nighttime, resulting in greater uncertainty in crash outcomes, or because appropriate response under darkness is difficult to come by (see, e.g., Kockelman and Ma 2004). When the largest truck is maneuvering a curve in the road at the time of the crash or at a sag in the road profile, the likelihood of fatality is predicted to drop. It could be that such roadway geometry increases driver awareness and/or encourages more cautious (e.g., slower) driving. On the other hand, uphill and downhill grades of $2 \%$ or more are predicted to have the opposite effect on crash severity. Interestingly and consistent with observations by Khattak et al. (2002) and Wang and Kockelman (2005), wet surface conditions are associated with less severe crashes. However, snowy or icy road conditions and the presence of fog greatly increase the likelihood of fatality. While one might expect drivers to exhibit more caution under such conditions, it could be that drivers simply do not realize how much caution is truly needed since such conditions occur with rarity. Not surprisingly, higher speed limits and any vehicle's speeding just before the crash result in more severe crashes. Somewhat surprisingly, however, when any driver is under the influence of illegal drugs or displaying other aggressive driving behavior (other than speeding), probability of the lowest crash severity is predicted to be higher. In the case of illegal drugs, the variance component is also predicted to increase, which ends up resulting in a slight increase in the probability of fatality as well.

Not surprisingly, the number of trucks, passenger vehicles, and non-motorists involved in the crash all increase the probability of a fatality, as do the number of passenger vehicle and truck occupants. As far as the characteristics of the largest truck involved, the number of trailers is predicted to increase the likelihood of severe injury and fatal crashes, while the total length and GVWR are predicted to reduce those likelihoods. If the largest truck is a single unit with no trailer, the likelihood of both low severity and fatality rise due to the positive effect of the variable on variance. Of course, these variables exhibit a great deal of correlation, so it would be difficult to make any strong conclusions simply based on isolating just one of these variables. The following presents a more detailed analysis of the largest truck type.

\section{Crash-Level Injury Severity and Costs by Largest Truck Type}

To further examine the effect of the largest truck's characteristics on crash injury severity, a simulation experiment was performed. Trucks were classified into five categories: single unit with no trailer, 0-trailer tractor, 1-trailer tractor, 2-trailer non-LCV (any 2-trailer HDT with both trailers measuring $28 \mathrm{ft}$ or less), and 2-trailer LCV (2-trailer HDTs where one or both trailers are longer than $28 \mathrm{ft}$ ). To perform the simulation, 5,000 observations were constructed by drawing randomly from the sample according to observation weights, and largest truck type 
characteristics were assigned randomly based on the sample collection of each truck type. Thus, for each truck type, 5,000 observations were simulated where the non-truck type variables were identical across the truck type simulated data points. Finally, the posterior parameter draws were used to find the distribution of crash severity outcomes according to the type of largest truck involved. Figure 2 illustrates the findings.

\section{Figure 2 goes here}

As shown in Figure 2, once involved in an injurious crash, 1-trailer HDTs are predicted to enjoy the lowest expected crash severity. The 2-trailer LCVs perform nearly the same as 2-trailer nonLCVs and about as well as SU trucks, at least in terms of fatal outcomes. This could be because drivers of such vehicles require more rigorous training and/or they are simply more cautious, so their crashes are less severe. The truck type that performs worst in this case is the 0-trailer tractor. Maybe this is because drivers of such vehicles feel they do not need to drive as carefully when a trailer is not being tow.

In any case, a broader impression of LCV risks requires a look at severity shares for non-injury crash outcomes, which are not recognized in the LTCCS data. Using the U.S. General Estimates System (GES) micro data (which provides crash data for all vehicle-involved crash types), from April 2001 to December 2003, estimates of non-injury and injury crash outcomes were found for each truck category. Unfortunately, the GES does not offer truck length data, so crash outcomes for 2-trailer non-LCVs and LCVs are assumed equal here. Based on this information, it appears that $12.4 \%, 13.1 \%, 13.9 \%$, and $19.1 \%$ of truck crashes result in injury when the largest truck is a single unit, 0-trailer tractor, 1-trailer tractor, and 2-trailer tractor, with the remaining proportions made up by non-injury and possible injury severity outcomes.

Taking it a step further, the GES data set can also be used to obtain estimates of the total number of crashes by largest truck type. Combining this with vehicle-miles-traveled information from the Vehicle Inventory and Use Survey (VIUS) from 2002, it was estimated that single-unit trucks were involved in crashes every $311,000(311 \mathrm{~K}) \mathrm{VMT}$, while 0-trailer, 1-trailer, and 2-trailer tractors were involved in crashes every $371 \mathrm{~K}, 422 \mathrm{~K}$, and $884 \mathrm{~K}$ VMT, respectively. Finally, to obtain crash cost estimates, one can refer to Zaloshnja and Miller's (2007) estimates of crash costs by injury severity, as shown in Table $7 .^{7}$

\section{Table 7 goes here}

With this new information, it is possible to characterize the distribution of total costs on a crash basis, as well as on a vehicle-miles-traveled basis, as shown in Figure 3. ${ }^{8}$ Figure 3 illustrates that on a per-crash basis, 2-trailer non-LCVs and LCVs have the highest associated costs by far, with

\footnotetext{
${ }^{7}$ Average fatalities are often valued much higher than $\$ 3 \mathrm{M}$ to $\$ 4 \mathrm{M}$ in the literature, and Zaloshnja and Miller's (2007) costs may be low. However, the main purpose of introducing these costs is to create a rating mechanism to relate the magnitudes of each crash type. Thus, the key assumption here is that the relative magnitude of costs, by severity level, are reasonable, which they appear to be.

${ }^{8}$ The reason the results are shown as distributions is that the parameters of the severity model are characterized by a posterior distribution rather than as point estimates. Thus, these cost estimate distributions represent uncertainty from the crash severity model.
} 
means of about $\$ 232 \mathrm{~K}$ and $\$ 222 \mathrm{~K}$, respectively. When one controls for crash rates by vehicle type, 1- and 2-trailer HDTs have nearly the same average crash costs at $\$ 0.255, \$ 0.263$, and \$0.251 per vehicle-mile for 1-trailer HDTs, 2-trailer non-LCVs, and 2-trailer LCVs, respectively. Single-unit trucks (with no trailer) and 0-trailer tractors are associated with the highest crash costs per VMT, averaging $\$ 0.350$ and $\$ 0.330$, respectively. Of course, on a per-ton-mile or perunit-volume basis, LCVs will fare even better, since, presumably, they carry more content.

\section{Figure 3 goes here}

These results suggest that LCVs are relatively safe. Overall, 2-trailer LCV estimates suggest they may be as safe as their 1-trailer HDT counterparts, on a mileage basis. Of course, on a crash basis, 2-trailer HDTs are less safe than all other truck types, due to their propensity to be involved in more serious crashes - once they are in a crash (which is less often, thanks to a variety of factors).

\section{CONCLUSIONS}

The paper analysis examined the impact of environmental, driver, and vehicle factors on injury severities resulting from large truck crashes by analyzing the U.S.'s recent Large Truck Crash Causation Study (LTCCS) data. Two regression models were developed to study both the maximum injury severity from a crash (over all involved individuals) and the maximum injury severity of occupants of all involved vehicles. Ordered probit (OP) and heteroskedastic ordered probit (HOP) models were examined, and estimation results suggest that the more flexible HOP specifications perform significantly better (thanks to permitting variation unobserved components).

The results of the two crash-conditioned models are generally consistent. For example, the probability of the least severe injury type was greatly increased (given an injurious large truck crash) when the crash occurred at a curve in the roadway, the crash occurred on a roadway sag, any truck involved was overweight, any driver was under the influence of illegal drugs, and/or any driver was exhibiting aggressive driving behavior (other than speeding). The probability of fatality is estimated to rise when non-bright lighting conditions are present, the road surface is snowy or icy, and/or fog is present. In addition, the number of involved passenger vehicle and truck occupants was estimated to increase the likelihood of a fatal outcome. While the number of truck trailers was estimated to increase the likelihood of fatality, total truck length and gross vehicle weight rating (GVWR) attributes were both estimated to reduce fatality likelihood. Taken together, these model estimates suggest 1-trailer trucks are associated with lower severity levels (assuming an injurious crash has occurred) and 0-trailer tractors are associated with the most severe injurious truck crashes, while single-unit trucks and 2-trailer non-LCVs and LCVs perform somewhere in the middle. Of course, one must be careful in drawing conclusions. The estimates here only relate to specific ranges of each variable. If truck length and/or GVWR increase past the levels common in the LTCCS sample, the model's estimates may not be valid.

Various researchers have found that LCVs enjoy lower crash rates than other HDTs (e.g., Woodrooffe 2001 and Montufar et al. 2007), as confirmed here by combining truck crash data from the GES and truck usage data from the VIUS. Once an analyst conditions on crash 
occurrence, he/she can evaluate the severity of such crashes, as performed here. While the crashlevel model results provided here suggest that LCVs (along with 2-trailer non-LCVs) may be associated with more severe and fatal injury crashes and the costs of those crashes may be highest in comparison to other truck types, such vehicles are associated with lower crash rates (per vehicle-mile traveled). After controlling for exposure, results suggested that LCVs enjoy significantly lower crash costs, per vehicle-mile traveled. This could be a result of any number of factors or combinations of those factors. For instance, LCV drivers are often better-trained and more experienced, many states restrict LCV use when road surfaces are snowy or icy, and LCVs are often restricted to higher-design routes, such as interstates (Abdel-Rahim 2009 and Regehr 2009).

Taken all together, the literature and these results suggest that LCVs vehicles deserve closer consideration, particularly if they offer opportunities for lowered transport costs and energy use without negatively impacting pavements, bridges, and other infrastructure elements.

\section{ACKNOWLEDGEMENTS}

The authors wish to recognize the Texas Department of Transportation for funding this research under TXDOT project number 0-6095, titled "Longer Combination Vehicles and Road Trains for Texas." The authors would also like to thank Ralph Craft and several anonymous reviewers for their suggestions.

\section{REFERENCES}

American Association of State Highway \& Transportation Officials (AASHTO), Report of the Subcommittee of Truck Size and Weight of the AASHTO Joint Committee on Domestic Freight Policy, AASHTO, 1995.

Abdel-Aty, M. A. Analysis of driver injury severity levels at multiple locations using ordered probit models. Journal of Safety Research 34(5): 597-603, 2003.

Abdel-Rahim, A., Berrio-Gonzales, S.G., Candia, G., Taylor, W. Longer Combination Vehicle Safety: A Comparative Crash Rate Analysis. Final Report. National Institute for Advanced Transportation Technology (NIATT) Report Number N06-21, Idaho, 2006.

Abdel-Rahim, A. Assistant Professor, Department of Civil Engineering, University of Idaho. Personal Interview, 2009.

Albert, J.H., Chib, S. Bayesian Analysis of Binary and Polychotomous Response Data. Journal of the American Statistical Association 88: 669-679, 1993.

Bedard, M., Guyatt, G. H., Stones, M. J. and Hirdes, J. P. The independent contribution of driver, crash, and vehicle characteristics to driver fatalities. Accident Analysis and Prevention 34(6): 717-727, 2002. 
California Department of Transportation (Caltrans). Longer Combination Vehicles Operational Tests. Available at www.dot.ca.gov/hq/traffops/trucks/exemptions/truck/lcv-op-test.pdf, 1983.

California Department of Transportation (Caltrans). Longer Combination Vehicles Operational Tests. Available at http://www.dot.ca.gov/hq/traffops/trucks/exemptions/lcvs.htm, 2009.

Campbell, K. L., Pettis, L.C. Accident Rates of Existing Longer Combination Vehicles. University of Michigan Transportation Research Institute, Ann Arbor, Michigan. Available at http://deepblue.lib.umich.edu/bitstream/2027.42/840/2/78795.0001.001.pdf, 1989.

Craft, R. Longer Combination Vehicles involved in Fatal Crashes, 1991-1996. Federal Highway Administration, Office of Motor Carrier Research and Standards, Washington DC. Available at http://www.fmcsa.dot.gov/documents/ab99-018.pdf, 1999.

Debauche, W., Decock, D. Working Group on Longer and Heavier Goods Vehicles (LHVs): Multidisciplinary Approach to the Issue). Belgian Road Research Centre. Appendix to the BRRC Bulletin Number 70, Brussels, Belgium. Available at http://www.brrc.be/pdf/bulletin_en/bul_en70t.pdf, 2007.

European Road Safety Observatory (ERSO). Heavy Goods Vehicles. Available at: http://www.erso.eu/knowledge/content/50_vehicle/heavy_goods_vehicles.htm . Last Accessed: July 20, 2009.

Farmer, C. M., Braver, E. R. and Mitter, E. L. Two-vehicle side impact crashes: The relationship of vehicle and crash characteristics to injury severity. Accident Analysis and Prevention 29(3): 399-406, 1997.

Federal Motor Carrier Safety Administration (FMCSA). Crash Statistics 2009. Available at http://www.ai.volpe.dot.gov/CrashProfile/n_overview.asp, 2009.

Federal Motor Carrier Safety Administration (FMCSA)., Motor Carrier Safety Progress Report, 2007. Available at: http://www.fmcsa.dot.gov/facts-research/facts-figures/analysisstatistics/MCSPR-12-31-07.htm. Last accessed: July 202009

Federal Motor Carrier Safety Administration (FMCSA). Large Truck Crash Facts. Available at http://www.fmcsa.dot.gov/facts-research/research-technology/report/Large-Truck-Crash-Facts2005/Index-2005LargeTruckCrashFacts.htm\#chap2, 2007 (Accessed July 1, 2009).

Forkenbrock, D.J., Hanley, P.F. Fatal Crash Involvement by Multiple-Trailer Trucks. Transportation Research Part A 37: 419-433, 2003.

Gamerman, D., Lopes, H.F. Markov Chain Monte Carlo: Stochastic Simulation for Bayesian Inference. Chapman \& Hall/CRC, Boca Raton, FL, 2006.

Gelman, A., Carlin, J.B., Stern, H.S., Rubin, D.B. Bayesian Data Analysis. Chapman \& Hall/CRC, Boca Raton, FL, 2004. 
Glaeser, K.P., Kaschner, R., Lerner, M., Roder, C.K., Weber, R., Wolf, A., Zander, U. Effects of New Vehicle Concepts on the Infrastructure of the Federal Trunk Road Network. Final report. Federal Highway Research Institute, Berlin, Germany. Available at http://www.bast.de/nn_42642/DE/Publikationen/Downloads/downloads/60-tonner-englischkurz,templateId=raw,property=publicationFile.pdf/60-tonner-englisch-kurz.pdf, 2006.

Greene, W. H. Econometric Analysis, Fifth Edition. Prentice Hall, New Jersey, 2002.

Grover, C., Knight, I., Okoro, F., Simmons, I., Couper, G., Massie, P., Smith, B. Automated Emergency Brake Systems: Technical Requirements, Costs and Benefits. Published Project Report Number 227. TRL Limited, Berkshire, United Kingdom. Available at http://ec.europa.eu/enterprise/automotive/projects/report_aebs.pdf, 2007

Hanley, P.F., Forkenbrock, D.J. Safety of passing longer combination vehicles on two-lane highways. Transportation Research Part A 39: 1-15, 2005.

Harkey D.L., Council, F.M., Zegeer, C.V. Operational Characteristics of Longer Combination Vehicles and Related Geometric Design Issues. Transportation Research Record 1523: 22- 28, 2006.

Khattak, A. J., Kantor, P. and Council, F. M. Role of adverse weather in key crash types on limited-access roadways. Transportation Research Record 1621: 10-19, 1998.

Khattak, A. J., Pawlovich, M. D., Souleyrette, R. R. and Hallmark, S. L. Factors related to more severe older driver traffic crash injuries. Journal of Transportation Engineering 128(3): 243-249, 2002.

Khattak, A. J. and Rocha, M. Are SUVs 'Supremely Unsafe Vehicles? Analysis of rollovers and injuries with sport utility vehicles. Transportation Research Record 1840: 167-177, 2003.

Kockelman, K.M., Ma, J. Freeway speeds and speed variations preceding crashes, within and across lanes. Journal of the Transportation Research Forum, 46(1), 2007.

Knight, I., Newton, W., Mckinnon, A., Palmer, A., Barlow, T., McCrae, I., Dodd, M., Couper, G., Davies, H., Daly, A., McMohan, W., Cook, E, Ramdas, V., Taylor, N. Longer and /or Longer and Heavier Goods Vehicles (LHVs): A Study of the Likely Effects if Permitted in the UK. Final Report. Published Project Report Number 285. TRL Limited, Berkshire, United Kingdom. Available at http://www.ciltuk.org.uk/pages/downloadfile?d=46AAD48B-7044-481981FA-753DF78D61AC\&a=stream, 2008.

Knipling, R. R. Comparison of Combination-Unit and Single-Unit Trucks in the Large Truck Crash Causation Study. Federal Motor Carrier Safety Administration Webinar, Virginia Tech Transportation Institute, 2008.

Kockelman, K. M. and Kweon, Y. J. Driver injury severity: An application of ordered probit 
models. Accident Analysis and Prevention 34(3), 2002, pp.313-321.

Kweon, Y.J. and Kockelman, K. M. Overall injury risk to different drivers: Combining exposure, frequency, and severity models. Accident Analysis and Prevention 35(4): 441, 450, 2003.

McCulloch, R., Rossi, P.E. An Exact Likelihood Analysis of the Multinomial Probit Model. Journal of Econometrics 64: 207-240, 1994.

Montufar, J., Regehr, J., Rempel, G., McGregor, R. Long Combination Vehicle (LCV) Safety Performance in Alberta: 1999-2005. Final Report. Alberta Infrastructure and Transportation Policy and Corporate Services Division, Canada. Available at http://www.transportation.alberta.ca/Content/docType61/production/LCVFinalReport2005.pdf, 2007.

O'Donnell, C.J. and Connor, D.H. Predicting the severity of motor vehicle accident injuries using models of ordered multiple choice. Accident Analysis and Prevention 28(6): 739-753, 1996.

Regehr, J. Department of Civil Engineering, University of Manitoba. Personal Interview, 2009.

Renshaw, N. Longer and Heavier Lorries (LHLs) and the Environment. Position Paper.

European Federation for Transport and Environment. Available at http://www.transportenvironment.org/Downloads-req-getit-lid-453.html, 2007.

RoadTransport. Longer, Heavier Vehicles (LHVs). Available at http://www.roadtransport.com/staticpages/longerheaviervehicleslhvs.htm. Last Accessed, July 2009

Vierth, I., Berell, H., McDaniel, J., Haraldsson, M., Hammarström, U., Yahya, M., Lindberg. G., Carlsson, A., Ögren, M., Björketun, U. The effects of Long and Heavy Trucks on the Transport System. Report on a government assignment. Swedish National Road and Transport Institute (VTI) Report 6105a, VTI Sweden. Available at http://www.vti.se/EPiBrowser/Publikationer\%20-\%20English/R605A.pdf, 2008.

US Department of Transportation - US DOT. Comprehensive Truck Size and Weight Study, Volume III, Scenario Analysis. US Department of Transportation, Washington, DC. Available at http://www.fhwa.dot.gov/reports/tswstudy/tswfinal.htm, 2000.

US Government Accounting Office (GAO). Truck Safety: The Safety of Longer Combination Vehicles is Unknown. Report RECD-92-66. Government Accounting Office, Washington, DC. 1992.

Wang, X., Kockelman, K.M. Use of Heteroskedastic Ordered Logit Model to Study Severity of Occupant Injury: Distinguishing Effects of Vehicle Weight and Type. Transportation Research Record 1908: 195-204, 2005. 
Wang, J. S., Knipling, R. R., Blincoe, L. J. The Dimensions of Motor Vehicle Crash Risk. Journal of Transportation and Statistics 2(1):19-43, 1999.

Woodrooffe, J. Long Combination Vehicle Safety Performance in Alberta, 1995 to 1998. Alberta, Canada. Available at http://www.transportation.alberta.ca/Content/docType61/production/LCVSafetyPerformanceRep ort.pdf., 2001.

Woodrooffe, J. Director, Transportation Research Institute, University of Michigan. Personal Interview, 2009.

Zaloshnja, E., Miller, T.R., Spicer, R.. Costs of Large Truck- and Bus-Involved Crashes (Final Report). Federal Motor Carrier Safety Administration, Washington, DC. Available at http://www.fmcsa.dot.gov/documents/ab01-005.pdf, 2000.

Zaloshnja, E., Miller, T.R.. Costs of Large Truck-involved Crashes in the United States. Accident Analysis and Prevention 36: 801-808, 2004.

Zaloshnja, E. and Miller, T.R. Unit Costs of Medium and Heavy Truck Crashes. Final Report for Federal Motor Carrier Safety Administration (FMCSA) and Federal Highway Administration (FHWA), Washington, D.C., 2007. 
(a) Vehicle-Level Model

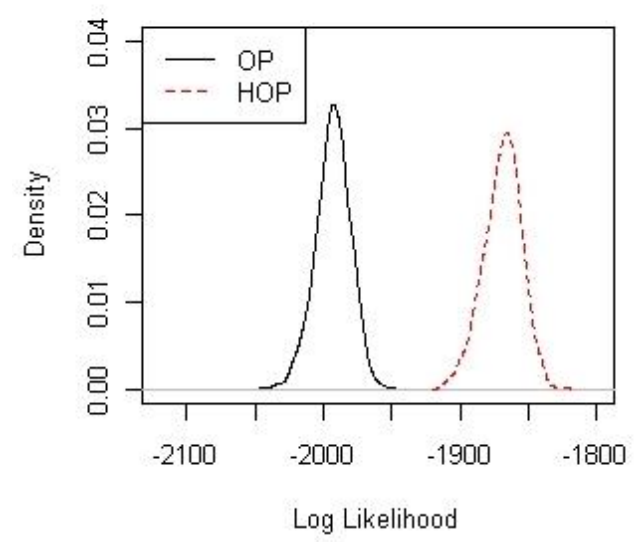

(b) Crash-Level Model

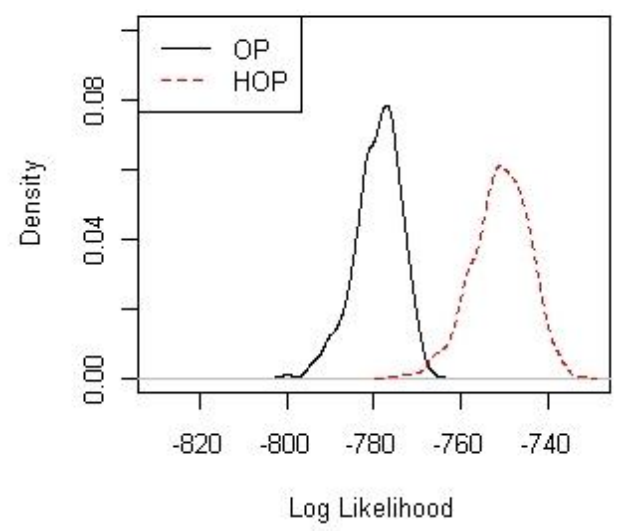

Figure 1: Log-Likelihood Distributions for OP and HOP Models of Injury Severity
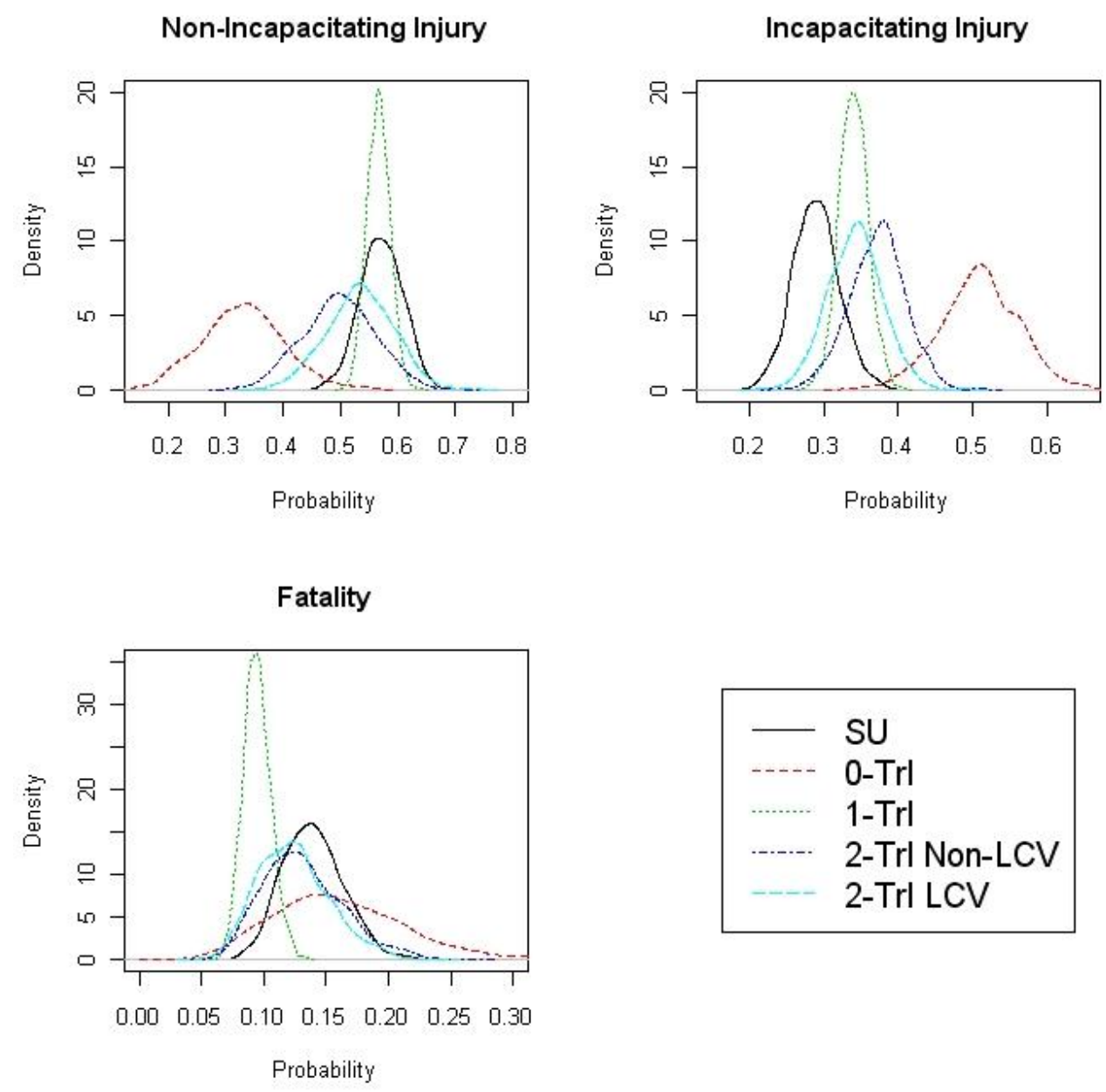

Figure 2: Distribution of Crash Severity Outcomes by Truck Type 

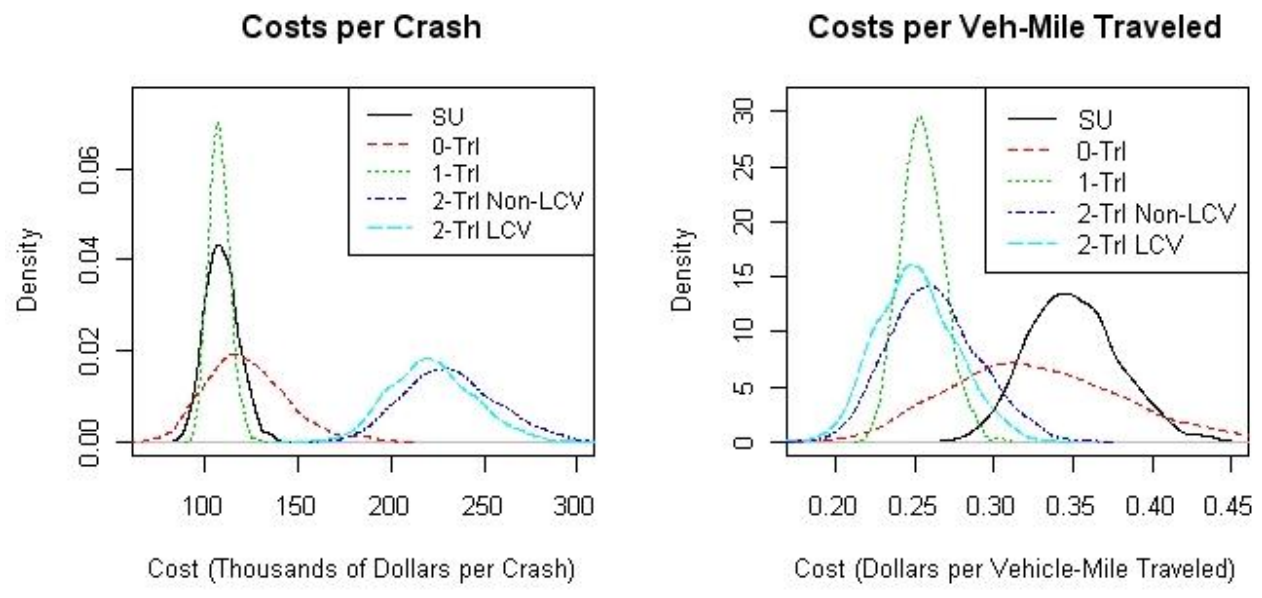

Figure 3: Per-Crash Cost Estimates, by Largest Involved-Truck Type 
Table 1: Maximum Injury Severity Statistics (LTCCS Survey Data)

\begin{tabular}{|c|c|c|c|c|}
\hline \multirow{2}{*}{ Outcome } & \multicolumn{2}{|c|}{ Vehicle-Level Model } & \multicolumn{2}{c|}{ Crash-Level Model } \\
\cline { 2 - 5 } & Wtd. Freq. & Wtd. \% & Wtd. Freq. & Wtd. \% \\
\hline No Injury & 695 & 36.7 & $\mathrm{n} / \mathrm{a}$ & $\mathrm{n} / \mathrm{a}$ \\
\hline Possible Injury & 13 & 0.7 & $\mathrm{n} / \mathrm{a}$ & $\mathrm{n} / \mathrm{a}$ \\
\hline Non-Incapacitating Injury & 728 & 38.4 & 501 & 54.3 \\
\hline Incapacitating Injury & 380 & 20.1 & 343 & 37.2 \\
\hline Killed & 78 & 4.1 & 78 & 8.5 \\
\hline
\end{tabular}


Table 2: Descriptive Statistics (Vehicle-Level, $n=1894$; Crash-Level, $n=922$ )

\begin{tabular}{|c|c|c|c|c|c|c|c|}
\hline & \multirow{2}{*}{ Variable } & \multicolumn{2}{|c|}{ Vehicle-Level } & \multicolumn{2}{|c|}{ Crash-Level } & \multirow[b]{2}{*}{ Min. } & \multirow[b]{2}{*}{ Max } \\
\hline & & Mean & Std. Dev. & Mean & Std. Dev. & & \\
\hline \multirow{19}{*}{ 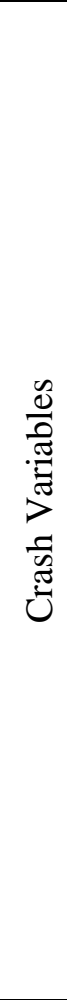 } & Number of Involved Trucks & $\mathrm{n} / \mathrm{a}$ & $\mathrm{n} / \mathrm{a}$ & 1.18 & 0.511 & 1 & 5 \\
\hline & $\begin{array}{l}\text { Number of Involved Passenger } \\
\text { Vehicles }\end{array}$ & 1.18 & 1.138 & 0.811 & 0.895 & 0 & 28 \\
\hline & Number of Involved Non-Motorists & 0.011 & 0.104 & 0.019 & 0.137 & 0 & 2 \\
\hline & Dark Indicator & $\mathrm{n} / \mathrm{a}$ & $\mathrm{n} / \mathrm{a}$ & 0.109 & 0.312 & 0 & 1 \\
\hline & Dark, but Lighted Indicator & 0.117 & 0.321 & 0.115 & 0.319 & 0 & 1 \\
\hline & Dusk/Dawn Indicator & 0.038 & 0.192 & 0.043 & 0.203 & 0 & 1 \\
\hline & Wet Surface Indicator & $\mathrm{n} / \mathrm{a}$ & $\mathrm{n} / \mathrm{a}$ & 0.159 & 0.365 & 0 & 1 \\
\hline & Snowy/Icy Surface Indicator & $\mathrm{n} / \mathrm{a}$ & $\mathrm{n} / \mathrm{a}$ & 0.017 & 0.128 & 0 & 1 \\
\hline & Snowing Indicator & 0.009 & 0.094 & $\mathrm{n} / \mathrm{a}$ & $\mathrm{n} / \mathrm{a}$ & 0 & 1 \\
\hline & Foggy Indicator & 0.004 & 0.063 & 0.004 & 0.061 & 0 & 1 \\
\hline & Other Weather Indicator & 0.013 & 0.113 & 0.013 & 0.112 & 0 & 1 \\
\hline & Overweight Indicator (Any Truck) & 0.071 & 0.257 & 0.060 & 0.237 & 0 & 1 \\
\hline & $\begin{array}{l}\text { Prescription Drug Indicator (Any } \\
\text { Driver) }\end{array}$ & $\mathrm{n} / \mathrm{a}$ & $\mathrm{n} / \mathrm{a}$ & 0.457 & 0.498 & 0 & 1 \\
\hline & Illegal Drug Indicator (Any Driver) & $\mathrm{n} / \mathrm{a}$ & $\mathrm{n} / \mathrm{a}$ & 0.068 & 0.252 & 0 & 1 \\
\hline & Fatigued Indicator (Any Driver) & 0.125 & 0.331 & $\mathrm{n} / \mathrm{a}$ & $\mathrm{n} / \mathrm{a}$ & 0 & 1 \\
\hline & Speeding Indicator (Any Driver) & 0.053 & 0.224 & 0.104 & 0.315 & 0 & 2 \\
\hline & $\begin{array}{l}\text { Other Aggression Indicator (Any } \\
\text { Driver) }\end{array}$ & 0.106 & 0.308 & 0.053 & 0.228 & 0 & 2 \\
\hline & Total Passenger Vehicle Occupants & $\mathrm{n} / \mathrm{a}$ & $\mathrm{n} / \mathrm{a}$ & 1.24 & 1.65 & 0 & 40 \\
\hline & Total Truck Occupants & $\mathrm{n} / \mathrm{a}$ & $\mathrm{n} / \mathrm{a}$ & 1.34 & 0.698 & 1 & 6 \\
\hline \multirow{10}{*}{ 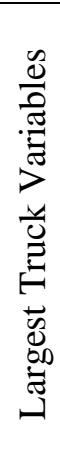 } & Number of Truck Trailers & 0.836 & 0.480 & 0.827 & 0.475 & 0 & 2 \\
\hline & Single-Unit Truck Indicator & 0.188 & 0.391 & 0.189 & 0.391 & 0 & 1 \\
\hline & Length $(\mathrm{ft})$ & 57.1 & 17.1 & 57.1 & 16.7 & 9.8 & 105 \\
\hline & GVWR (1,000 lbs) & 103 & 32.8 & 103 & 32.6 & 10.0 & 105 \\
\hline & Rural Non-Freeway Indicator & $\mathrm{n} / \mathrm{a}$ & $\mathrm{n} / \mathrm{a}$ & 0.314 & 0.464 & 0 & 1 \\
\hline & Curved Road Indicator & $\mathrm{n} / \mathrm{a}$ & $\mathrm{n} / \mathrm{a}$ & 0.333 & 0.471 & 0 & 1 \\
\hline & Uphill/Downhill Grade Indicator & $\mathrm{n} / \mathrm{a}$ & $\mathrm{n} / \mathrm{a}$ & 0.370 & 0.483 & 0 & 1 \\
\hline & Road Crest Indicator & $\mathrm{n} / \mathrm{a}$ & $\mathrm{n} / \mathrm{a}$ & 0.025 & 0.156 & 0 & 1 \\
\hline & Road Sag Indicator & $\mathrm{n} / \mathrm{a}$ & $\mathrm{n} / \mathrm{a}$ & 0.005 & 0.072 & 0 & 1 \\
\hline & Speed Limit (mph) & $\mathrm{n} / \mathrm{a}$ & $\mathrm{n} / \mathrm{a}$ & 51.7 & 11.9 & 15 & 75 \\
\hline \multirow{11}{*}{ 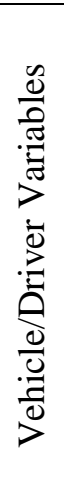 } & Number of Lanes (one directions) & 2.93 & 1.22 & $\mathrm{n} / \mathrm{a}$ & $\mathrm{n} / \mathrm{a}$ & 1 & 7 \\
\hline & Rural Non-Freeway Indicator & 0.293 & 0.455 & $\mathrm{n} / \mathrm{a}$ & $\mathrm{n} / \mathrm{a}$ & 0 & 1 \\
\hline & Rural Freeway Indicator & 0.163 & 0.369 & $\mathrm{n} / \mathrm{a}$ & $\mathrm{n} / \mathrm{a}$ & 0 & 1 \\
\hline & Urban Freeway Indicator & 0.359 & 0.480 & $\mathrm{n} / \mathrm{a}$ & $\mathrm{n} / \mathrm{a}$ & 0 & 1 \\
\hline & Uphill Grade Indicator & 0.162 & 0.368 & $\mathrm{n} / \mathrm{a}$ & $\mathrm{n} / \mathrm{a}$ & 0 & 1 \\
\hline & Illegal Drug Indicator & 0.041 & 0.199 & $\mathrm{n} / \mathrm{a}$ & $\mathrm{n} / \mathrm{a}$ & 0 & 1 \\
\hline & Vehicle Occupants & 1.29 & 0.712 & $\mathrm{n} / \mathrm{a}$ & $\mathrm{n} / \mathrm{a}$ & 1 & 11 \\
\hline & Truck Trailers & 0.468 & 0.539 & $\mathrm{n} / \mathrm{a}$ & $\mathrm{n} / \mathrm{a}$ & 0 & 2 \\
\hline & Bus Indicator & 0.002 & 0.046 & $\mathrm{n} / \mathrm{a}$ & $\mathrm{n} / \mathrm{a}$ & 0 & 1 \\
\hline & Motorcycle Indicator & 0.003 & 0.053 & $\mathrm{n} / \mathrm{a}$ & $\mathrm{n} / \mathrm{a}$ & 0 & 1 \\
\hline & Truck Indicator & 0.587 & 0.492 & $\mathrm{n} / \mathrm{a}$ & $\mathrm{n} / \mathrm{a}$ & 0 & 1 \\
\hline
\end{tabular}


Table 3: Estimation Results for Vehicle-Level OP and HOP Models

\begin{tabular}{|c|c|c|c|c|c|c|}
\hline \multirow{3}{*}{ Variable } & \multirow{2}{*}{\multicolumn{2}{|c|}{$\begin{array}{c}\text { OP } \\
\text { Main Effects }\end{array}$}} & \multicolumn{4}{|c|}{ HOP } \\
\hline & & & \multicolumn{2}{|c|}{ Main Effects } & \multicolumn{2}{|c|}{ Variance Effects } \\
\hline & Mean & 95\% Interval & Mean & 95\% Interval & Mean & $95 \%$ Interval \\
\hline Constant & 1.29 & $(0.986,1.59)$ & 2.04 & $(1.78,2.32)$ & -1.71 & $(-2.06,-1.31)$ \\
\hline \multicolumn{7}{|l|}{ Crash Variables } \\
\hline \# Passenger Vehicles & -0.276 & $(-0.314,-0.240)$ & -0.707 & $(-0.781,-0.626)$ & 0.393 & $(0.349,0.435)$ \\
\hline \# Non-Motorists & -0.892 & $(-1.34,-0.480)$ & -3.64 & $(-10.4,-1.07)$ & 1.50 & $(0.331,2.86)$ \\
\hline Dark, but Lighted & 0.201 & $(0.081,0.328)$ & 0.124 & $(0.031,0.224)$ & $\mathrm{n} / \mathrm{a}$ & $\mathrm{n} / \mathrm{a}$ \\
\hline Dusk/Dawn & 0.115 & $(-0.093,0.295)$ & 0.142 & $(-0.002,0.265)$ & -0.343 & $(-0.627,-0.073)$ \\
\hline Snowing & -0.385 & $(-0.787,-0.007)$ & -0.094 & $(-0.417,0.114)$ & -0.835 & $(-1.98,0.165)$ \\
\hline Foggy & 0.261 & $(-0.335,0.821)$ & 0.260 & $(0.124,0.415)$ & -2.98 & $(-4.17,-1.87)$ \\
\hline Other Weather & -0.279 & $(-0.658,0.086)$ & -0.053 & $(-0.218,0.112)$ & -0.273 & $(-0.771,0.207)$ \\
\hline Overweight (Any Truck) & -0.181 & $(-0.355,-0.020)$ & -0.177 & $(-0.341,-0.027)$ & $\mathrm{n} / \mathrm{a}$ & $\mathrm{n} / \mathrm{a}$ \\
\hline Fatigued (Any Driver) & 0.169 & $(0.052,0.282)$ & 0.104 & $(0.014,0.189)$ & -0.214 & $(-0.352,-0.075)$ \\
\hline Speeding (Any Driver) & -0.278 & $(-0.492,-0.072)$ & -0.220 & $(-0.403,-0.028)$ & -0.055 & $(-0.308,0.209)$ \\
\hline $\begin{array}{l}\text { Other Aggression (Any } \\
\text { Driver) }\end{array}$ & 0.397 & $(0.227,0.554)$ & 0.210 & $(0.066$ & 0.101 & $(-0.09$ \\
\hline \multicolumn{7}{|l|}{ Largest Truck Variables } \\
\hline \# Truck Trailers & 0.199 & $(0.036,0.365)$ & 0.219 & $(0.059,0.376)$ & 0.167 & $(-0.082,0.411)$ \\
\hline Single-Unit Truck & -0.116 & $(-0.289,0.065)$ & -0.153 & $(-0.292,0.001)$ & 0.319 & $(0.065,0.555)$ \\
\hline Length (ft) & -0.005 & $(-0.009,-0.001)$ & -0.011 & $(-0.014,-0.007)$ & 0.011 & $(0.006,0.017)$ \\
\hline GVWR $(10,000 \mathrm{lbs})$ & -0.010 & $(-0.030,0.010)$ & -0.005 & $(-0.022,0.012)$ & -0.031 & $(-0.058,-0.005)$ \\
\hline \multicolumn{7}{|l|}{ Vehicle/Driver Variables } \\
\hline $\begin{array}{l}\text { Number of Lanes (one } \\
\text { direction) }\end{array}$ & -0.041 & $4,-0.009)$ & -0.021 & .014) & 0.024 & $(-0.021,0.067)$ \\
\hline Rural Non-Freeway & 0.161 & $(0.041,0.272)$ & 0.177 & $(0.081,0.275)$ & -0.071 & $(-0.186,0.044)$ \\
\hline Rural Freeway & 0.133 & $(-0.006,0.261)$ & 0.114 & $(-0.002,0.232)$ & $\mathrm{n} / \mathrm{a}$ & $\mathrm{n} / \mathrm{a}$ \\
\hline Urban Freeway & 0.104 & $(-0.006,0.211)$ & 0.061 & $(-0.038,0.165)$ & $\mathrm{n} / \mathrm{a}$ & $\mathrm{n} / \mathrm{a}$ \\
\hline Uphill Grade & 0.077 & $(-0.018,0.185)$ & 0.089 & $(0.010,0.171)$ & $\mathrm{n} / \mathrm{a}$ & $\mathrm{n} / \mathrm{a}$ \\
\hline Illegal Drug & 0.253 & $(0.076,0.432)$ & 0.102 & $(-0.041,0.239)$ & $\mathrm{n} / \mathrm{a}$ & $\mathrm{n} / \mathrm{a}$ \\
\hline Vehicle Occupants & 0.040 & $(-0.009,0.087)$ & 0.013 & $(-0.028,0.053)$ & $\mathrm{n} / \mathrm{a}$ & $\mathrm{n} / \mathrm{a}$ \\
\hline Truck Trailers & -0.178 & $(-0.305,-0.042)$ & 0.004 & $(-0.125,0.140)$ & -0.272 & $(-0.444,-0.102)$ \\
\hline Bus & -0.444 & $(-1.14,0.217)$ & -0.734 & $(-1.18,-0.341)$ & $\mathrm{n} / \mathrm{a}$ & $\mathrm{n} / \mathrm{a}$ \\
\hline Motorcycle & 0.489 & $(-0.114,1.12)$ & 0.291 & $(-1.99,4.08)$ & 1.74 & $(0.677,3.11)$ \\
\hline Truck & -0.726 & $(-0.860,-0.592)$ & -1.13 & $(-1.28,-1.01)$ & 0.621 & $(0.437,0.792)$ \\
\hline \multicolumn{7}{|l|}{ Structural Parameters } \\
\hline Std. Dev. & 0.634 & $(0.596,0.677)$ & $\mathrm{n} / \mathrm{a}$ & $\mathrm{n} / \mathrm{a}$ & $\mathrm{n} / \mathrm{a}$ & $\mathrm{n} / \mathrm{a}$ \\
\hline Threshold 3 & 1.41 & $(1.36,1.46)$ & 1.33 & $(1.29,1.37)$ & $\mathrm{n} / \mathrm{a}$ & $\mathrm{n} / \mathrm{a}$ \\
\hline Observations & & 1,894 & & & & \\
\hline
\end{tabular}


Table 4: Average Variable Effects (per Unit Change) on Outcome Severity in the VehicleLevel HOP Model

\begin{tabular}{|l|c|c|c|c|}
\hline & \multicolumn{4}{|c|}{ Probability Change in Outcome } \\
\hline Crash Variables & Non-Injury & $\begin{array}{c}\text { Non-Incap. } \\
\text { Injury }\end{array}$ & Incap. Injury & Fatality \\
\hline \# Passenger Vehicles & 0.269 & -0.144 & -0.081 & -0.044 \\
\hline \# Non-Motorists & 0.120 & -0.215 & -0.021 & 0.116 \\
\hline Dark, but Lighted & -0.072 & 0.045 & 0.015 & 0.012 \\
\hline Dusk/Dawn & -0.109 & 0.138 & -0.013 & -0.016 \\
\hline Snowing & 0.091 & -0.029 & -0.040 & -0.023 \\
\hline Foggy & -0.491 & 0.561 & -0.044 & -0.026 \\
\hline Other Weather & 0.046 & -0.008 & -0.023 & -0.015 \\
\hline Overweight (Any Truck) & 0.101 & -0.073 & -0.016 & -0.011 \\
\hline Fatigued (Any Driver) & -0.069 & 0.088 & -0.007 & -0.012 \\
\hline Speeding (Any Driver) & 0.131 & -0.093 & -0.023 & -0.015 \\
\hline Other Aggression & -0.114 & 0.043 & 0.032 & 0.040 \\
\hline Largest Truck Variables & & & & \\
\hline \# Truck Trailers & -0.122 & 0.043 & 0.033 & 0.046 \\
\hline Single-Unit Truck & 0.072 & -0.108 & 0.008 & 0.029 \\
\hline Length (10 ft) & 0.058 & -0.058 & -0.004 & 0.004 \\
\hline GVWR (10,000 lbs) & 0.033 & 0.032 & -0.026 & -0.038 \\
\hline Vehicle/Driver Variables & & & & \\
\hline \# Lanes (one direction) & 0.011 & -0.012 & 0.000 & 0.001 \\
\hline Rural Non-Freeway & -0.106 & 0.083 & 0.015 & 0.008 \\
\hline Rural Freeway & -0.066 & 0.041 & 0.013 & 0.011 \\
\hline Urban Freeway & -0.035 & 0.024 & 0.007 & 0.005 \\
\hline Uphill Grade & -0.052 & 0.033 & 0.010 & 0.008 \\
\hline Illegal Drug & -0.059 & 0.036 & 0.012 & 0.010 \\
\hline Vehicle Occupants & -0.007 & 0.004 & 0.002 & 0.002 \\
\hline Truck Trailers & 0.000 & 0.039 & -0.020 & -0.019 \\
\hline Bus & 0.342 & -0.281 & -0.038 & -0.023 \\
\hline Motorcycle & -0.015 & -0.307 & -0.009 & 0.331 \\
\hline Truck & 0.611 & -0.449 & -0.113 & -0.049 \\
\hline
\end{tabular}


Table 5: Estimation Results for Crash-Level OP and HOP Models

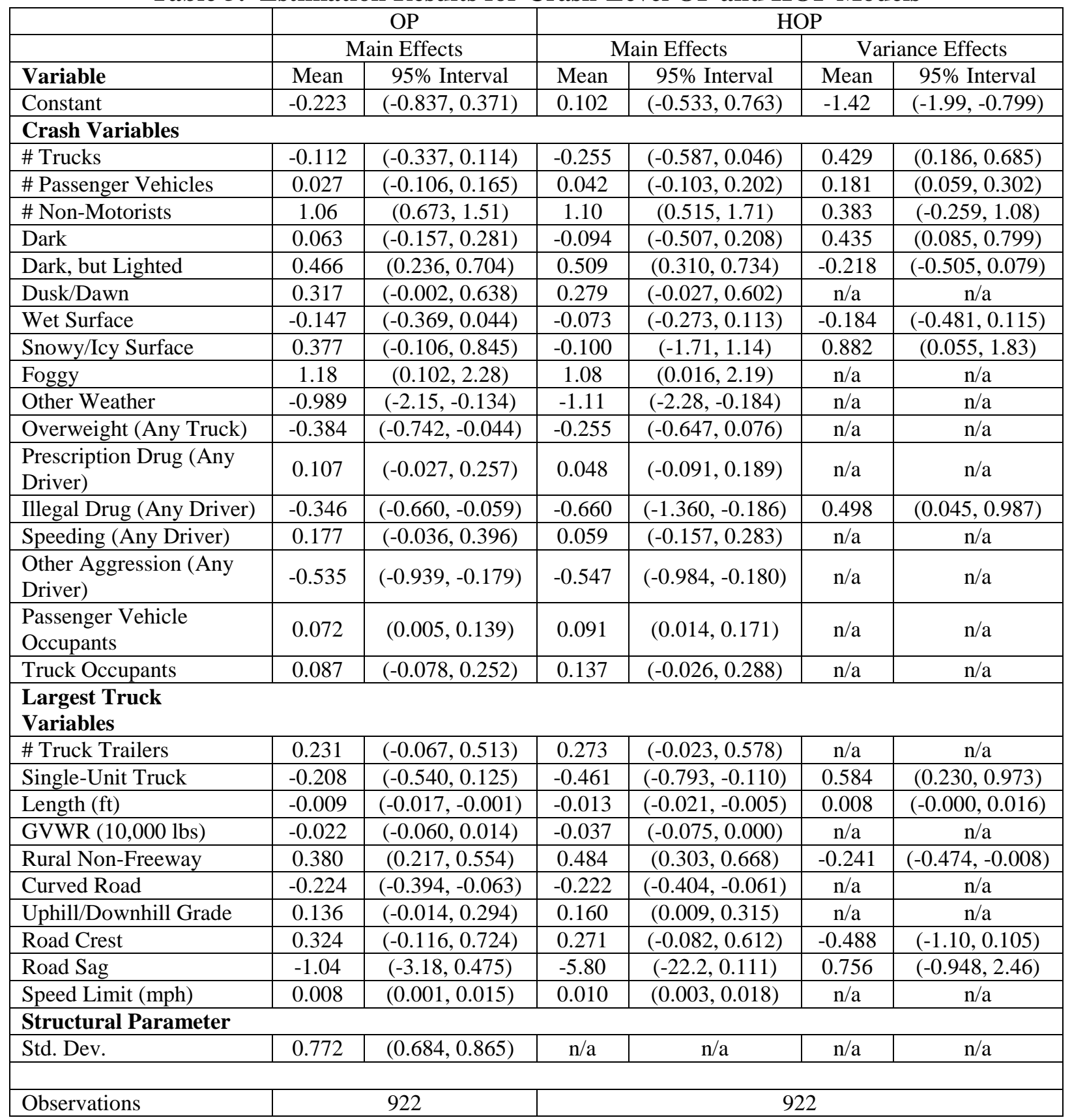

Note: No thresholds were estimated here since only three injury categories correspond to crash-level observations (and two thresholds have been fixed, to ensure model identification). 
Table 6: Average Variable Effects (per Unit Change) on Outcome Severity in the CrashLevel HOP Model

\begin{tabular}{|l|c|c|c|}
\hline & \multicolumn{2}{|c|}{ Probability Change in Outcome } \\
\hline Crash Variables & $\begin{array}{c}\text { Non-Incap. } \\
\text { Injury }\end{array}$ & Incap. Injury & Fatality \\
\hline \# Trucks & 0.036 & -0.093 & 0.057 \\
\hline \# Passenger Vehicles & -0.028 & -0.020 & 0.048 \\
\hline \# Non-Motorists & -0.219 & -0.101 & 0.320 \\
\hline Dark & 0.001 & -0.085 & 0.084 \\
\hline Dark, but Lighted & -0.260 & 0.183 & 0.077 \\
\hline Dusk/Dawn & -0.129 & 0.063 & 0.067 \\
\hline Wet Surface & 0.051 & -0.006 & -0.045 \\
\hline Snowy/Icy Surface & -0.038 & -0.150 & 0.188 \\
\hline Foggy & -0.392 & 0.012 & 0.379 \\
\hline Other Weather & 0.325 & -0.247 & -0.078 \\
\hline Overweight (Any Truck) & 0.109 & -0.074 & -0.035 \\
\hline Prescription Drug (Any Driver) & -0.022 & 0.013 & 0.009 \\
\hline Illegal Drug (Any Driver) & 0.154 & -0.166 & 0.012 \\
\hline Speeding (Any Driver) & -0.028 & 0.015 & 0.013 \\
\hline Other Aggression (Any Driver) & 0.221 & -0.156 & -0.065 \\
\hline Passenger Vehicle Occupants & -0.038 & 0.011 & 0.027 \\
\hline Truck Occupants & -0.061 & 0.022 & 0.038 \\
\hline Largest Truck Variables & & & \\
\hline \# Truck Trailers & -0.123 & 0.065 & 0.058 \\
\hline Single-Unit Truck & 0.123 & -0.174 & 0.050 \\
\hline Length (10 ft) & 0.052 & -0.043 & -0.009 \\
\hline GVWR (10,000 lbs) & 0.016 & -0.009 & -0.007 \\
\hline Rural Non-Freeway & -0.236 & 0.182 & 0.054 \\
\hline Curved Road & 0.100 & -0.063 & -0.037 \\
\hline Uphill/Downhill Grade & -0.074 & 0.042 & 0.031 \\
\hline Road Crest & -0.161 & 0.187 & -0.026 \\
\hline Road Sag & 0.347 & -0.299 & -0.048 \\
\hline Speed Limit (mph) & -0.046 & 0.027 & 0.019 \\
\hline & & & \\
\hline
\end{tabular}


Table 7: Crash Cost Estimates (in 1,000's of 2005 dollars) by Injury Severity and Truck Type Involved (Source: Zaloshnja and Miller 2007)

\begin{tabular}{|l|c|c|c|c|}
\hline Crash Severity & Single Unit & 0-Trailer & 1-Trailer & 2- or 3-Trailer \\
\hline No Injury & $\$ 13.3$ & 19.1 & 15.7 & 24.9 \\
\hline Possible Injury & 62.4 & 64.3 & 91.0 & 116.9 \\
\hline Non-Incapacitating Injury & 198.2 & 173.5 & 171.7 & 244.1 \\
\hline Incapacitating Injury & 640.5 & 381.3 & 437.8 & 1,292 \\
\hline Killed & 3,136 & 3,173 & 3,834 & 3,353 \\
\hline
\end{tabular}

